UCRL-JC-123860

Preprint

\title{
LLNL \\ Certification \\ Methodology
}

\author{
James Rothfuss \\ Computer Security Organization \\ Lawrence Livermore National Laboratory \\ Livermore, CA 94550 \\ rothfuss1@llnl.gov \\ (510)422-9452
}

RECEIVED

APR 291996

OSTI

\section{8th DOE Computer Security Group \\ Training Conference \\ April 24, 1996 \\ Seattle, Washington}

April 17, 1996

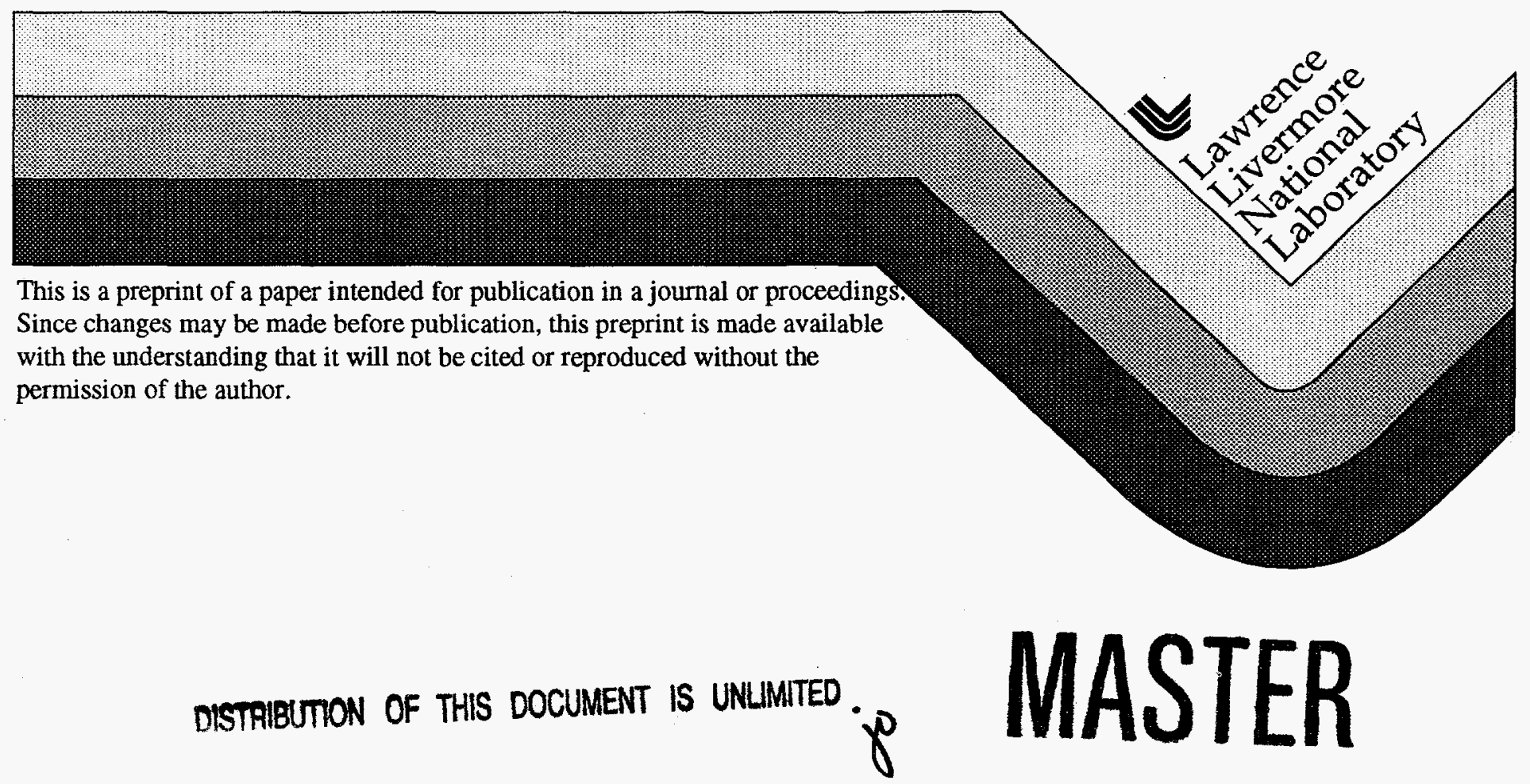




\section{DISCLAIMER}

This document was prepared as an account of work sponsored by an agency of the United States Government. Neither the United States Government nor the University of California nor any of their employees, makes any warranty, express or implied, or assumes any legal liability or responsibility for the accuracy, completeness, or usefulness of any information, apparatus, product, or process disclosed, or represents that its use would not infringe privately owned rights. Reference herein to any specific commercial product, process, or service by trade name, trademark, manufacturer, or otherwise, does not necessarily constitute or imply its endorsement, recommendation, or favoring by the United States Government or the University of California. The views and opinions of authors expressed herein do not necessarily state or reflect those of the United States Government or the University of California, and shall not be used for advertising or product endorsement purposes. 


\author{
LLNL Certification Methodology \\ to appear in the 18th DOE Computer Security Group Training Conference \\ James Rothfuss \\ Computer Security Organization \\ Lawrence Livermore National Laboratory \\ Livermore, CA 94550
}

April 24th, 1996

\begin{abstract}
The certification of classified computing systems is the process of ensuring that a system is in compliance with DOE order 471.2 and an approved AIS security plan. At Lawrence Livermore National Laboratory we have developed a standard certification methodology that can be used on most of our classified systems. The documentation for the methodology consists of an inspector's guideline, specific inspection criteria, and system function tests. Since operating systems vary greatly, individual information sheets for system function tests have been developed for various operating systems. These information sheets not only help the inspector to check various functions, they also give one or more ways that the system manager can configure the system to meet security requirements. This paper will introduce the LLNL certification methodology.
\end{abstract}

\section{What is certification?}

When an LLNL program decides that compute facilities are needed to process classified information, their first step is to write a computer security plan describing how the system will be protected. The plan is reviewed by the site Computer Security Organization (CSO) and then conveyed to the DOE Designated Accrediting Authority (DAA) for review and approval. Once approved the program can proceed with the implementation of the system security with the assurance that their system will be accredited for classified processing if they comply with their approved plan.. Once the program is confident that they have met all the requirements of their plan, the CSO inspects the system, allowing the Computer Security Site Manager (CSSM) to certify to the DAA that the system is operating according to the plan.

\section{Replacing the Self Certify Program}

In the recent past, the CSSM relied heavily on the program's Computer System Security Officers (CSSOs) to self-certify their systems. The CSO acted in a monitoring capacity rather than an active participate. Although this method effectively reduced the burden on the CSO, it had several disadvantages. Each CSSO could develop their own certification methods. With over 70 separate AIS plans covering about 1600 computers, allowing each to have a different method resulted in numerous inconsistencies across the site. Also, since the CSSOs did not have any direct interactions with DOE and limited interactions with the $\mathrm{CSO}$, disconnects started forming between the CSSOs' computer security implementations and those described by the DOE order. In 1994, the CSSM decided that the CSO needed to take a more active part in system certification and asked me to create a standard testing and assurance process. 


\section{Not Just Certification}

One of my early encounters with testing and assurance was escorting the DOE inspectors as they examined LLNL systems. This was a helpful learning experience and gave me great insight into the compliance oriented criteria the DOE inspectors used as their reference. It soon became apparent that most CSSOs, although technically astute, did not have a thorough knowledge of DOE compliance issues. CSSOs, eager to display their technical security knowledge to DOE inspectors, may emphasize their defenses against the latest "hacker" techniques, but would ignore compliance concerns such as detailed system documentation. Because of this difference between the inspectors' expectations and CSSOs' perspective, the CSSOs would often fail to "showcase" compliance issues, giving the impression that they are out of compliance. I quickly came to the conclusion that the certification process should not only be an assurance mechanism for the CSO and DOE, but also needed to be a learning process for the CSSO.

I wanted to embed a learning component into the standard testing and assurance process. The first part of the process evolved into a CSSO interview conducted by a CSO representative. The fact that it is an interview, as opposed to a questionnaire or test, is significant. An interview allows for immediate correction of any misconceptions and a chance for the CSO to strengthen the CSSO's knowledge with additional background information. Before the interview takes place, the CSSO is given a copy of the questions. Each question has a reference to the DOE order, LLNL policy documents, or the AIS plan. The CSSO is informed that this is not a "closed book" interview and is encouraged to look up the answers ahead of time. This is not a "60 minutes" style interview designed to embarrass or "trick" the CSSO. The goal of the interview is to familiarizes the CSSO with the requirements documents, to give the CSSO practice at responding to interview questions in a succinct manner, and finally to give the CSO the assurance that the CSSO knows, or is capable of finding, the security requirements for their system.

\section{Security is a Team Effort}

The computer security of a classified system requires a great many technical and administrative procedures. Unfortunately, since a lot of effort is expended creating and documenting these procedures, the tendency often exists to neglect informing the users about the procedures. As part of the system certification, I found that it is important to check that everyone involved has been informed of their computer security responsibilities. To do this I created system administrator, computer security escort, and user interviews. Each of these three interviews is tailored to the specific area of responsibility. For instance, I would expect a user to know that they must have CSSO approval before moving equipment, but I would not expect them to know, or care, how the CSSO tracks that equipment.

These interviews are conducted similar to the CSSO interview. The CSSO is given the list of questions ahead of time and given the discretion to prepare the prospective interviewees by whatever means they feel most comfortable. Most CSSO's disseminate the questions. Some give a special training class. A few, especially those with smaller systems, will do "one on one" training.

Often during the interviews I tell the interviewee that this is not a test of their 
knowledge, but a test of the CSSOs training process. Not only is it true, but it usually reduces the interviewee's tension level and results in a better interview. I have never had a CSSO object to this approach since a smooth interview is to the CSSO's benefit.

I have found that user interviews create a subtle by-product. The CSSOs often "encourage" the users to learn their responsibilities by revealing that CSO is going to do random user interviews. If I were to bypass the user interviews, the creditability of the CSSO's "encouragement" would be undermined. So, even if it is obvious that the CSSO is doing adequate training, I always do a couple of user interviews.

\section{Show me}

The interviews are often very telling, but they do not always give the complete story. Very few people will lie, but their human nature will cause them to exaggerate the positive. For instance, a CSSO might say "I have the procedure in place" when, what they really mean is "I have a procedure formulated in my head that I am currently using, but I haven't had time to write it down and I plan on catching up with the documentation in the very near future". Unfortunately, if a written procedure is needed to meet compliance, the CSSM cannot certify the system until the procedure is fully in place. To guard against this type of exaggeration, the assurance process provides a checklist for spot inspecting the environment and documentation.

As in the case of the interviews, the CSSO is given the checklist ahead of time. One might think that an unscrupulous CSSO could concentrate only on those items that he/she knows the CSO will check. Although this is possible, my experience has been that a CSSO who is unable to bring a system into compliance in a small area will have problems with all aspects of the system, even those that he/she knows are going to be inspected. The checklist is comprehensive enough that I am confident that a CSSO with the ability to meet its criteria will also meet all the compliance standards. Furthermore, the CSSO is made aware that even though, for the most part, the CSO confines itself to the checklist, the CSO has the option to inquire into any aspect of the system.

\section{Fire up the Computer}

When most people think of computer security, they think of the software and hardware protecting the system's data. A fact that is obvious, but often overlooked, is that as the physical and administrative security surrounding the system becomes stronger, software and hardware security becomes less important. On classified systems, the physical and administrative security is intense when compared to most unclassified systems. With this in mind, it is not surprising that the technical requirements for a protection index 0 system are not overly burdensome. There are however, a few things that need to be checked, mostly concerning passwords, user accounts, and auditing. As part of the assurance process, a set of function tests have been developed to ensure that all appropriate functions have been "turned on".

Although the technical criteria is rather small, the proliferation of operating systems and the number of different ways to meet the criteria sometimes makes this seemingly simple task of "turning on" the functions into a formidable challenge. LLNL uses everything from Apple Macintosh computers to 256 processor Meiko machines to process classified information; 
each with varying degrees of security functionality built into the operating system. The CSO's philosophy is that each CSSO is responsible for discovering the technical means of meeting the technical requirements. However, so that each new system using similar operating systems will not have to "reinvent the wheel", CSO has taken on the additional endeavor of documenting how the first pioneer into a new operating system meets the requirements. This documentation takes the official form of operating system (OS) specific guidelines. If a new system is preparing for accreditation, and uses an OS that has already successfully met the criteria, the guidelines can be used to quickly set it up in a similar manner. As always, the final approval is determined by meeting the requirements, not how those requirements are met. This leaves the CSSO the choice to use the guidelines or to use other unique methods.

\section{Carbon Copies}

DOE order 471.2 and it's computer security manual (5639.6A-1) are very prescriptive. Sometimes, when system flexibility is paramount, the order's prescriptive nature is a disadvantage. But, in the case of a certification program, the prescriptive nature acts to our advantage. Since each approved CS plan must meet DOE order criteria, variation from one plan to the next is very limited. After writing individual testing and assurance criteria for several systems, I came to the conclusion that $99 \%$ of the criteria stays the same. We currently have a set of standard interview questions, inspection checklist items, and function tests that cover most issues. All of these documents are in electronic word processor form and system specific criteria, when needed, is easily added.

\section{Epilogue}

Having a standardize criteria for testing and assurance has led to a higher level of consistency across the classified systems at LLNL. Adding a learning component to the activity has resulted in knowledgeable CSSOs who are more familiar with the DOE orders and are better able to understand the classified computing requirements that are important. Through this process the CSO has become a focal point for both formal and informal information sharing across systems. Although this new process has placed extra burden on the CSO, the overall result across LLNL has been better utilization of LLNL resources and better compliance with DOE orders. 


\section{DISCLATMBRR}

Portions of this document may be illegible in electronic image products. Images are produced from the best available original document. 